\title{
Cutis verticis gyrata: a new case
}

\section{Fatima-Zahra Kettani, Fouzia Hali, Kenza Baline, Soumia Chiheb}

\author{
Department of Dermatology, CHU Ibn Rochd, Casablanca, Morrocco
}

Corresponding author: Dr. Fatima-Zahra Kettani, E-mail: kettani.fatimazohra@gmail.com

\section{INTRODUCTION}

Cutis verticis gyrata $(\mathrm{CVG})$ is a condition in which excessive growth of the scalp skin leads to the formation of furrows that resemble a cerebriform pattern and cannot be corrected by external pressure. There are two forms: primary (essential and nonessential) and secondary [1]. We report a female patient with primary essential CVG.

\section{Observation}

A 43-year-old female patient, born to non-blood-related parents, was admitted for well-established convoluted skin of the parietal and occipital scalp evolving since 2 years (Fig. 1). There was no alopecia and no difference in the distribution of hair over the folds or in the ridges. There was no medical history of illnesses and no previous skin problems. Laboratory data, including hemogram, AST, ALT, alkaline phosphatase, creatinine, urea, free T4, TSH, prolactin, basal serum cortisol, and TPHA/VDRL, were found to be within normal limits. Cerebral MRI and mammography were normal. The diagnosis of our patient was more consistent with primary essential CVG. The patient did not agree to a skin biopsy and did not wish to undergo any surgical repair.

\section{DISCUSSION}

CVG diagnosis is based on clinical examination. The primary CVG (PCVG) is relatively rare and is subdivided in two groups: essential and non-essential CVG. The essential CVG or idiopathic CVG is generally not associated to other abnormalities. The non-essential CVG is generally associated to

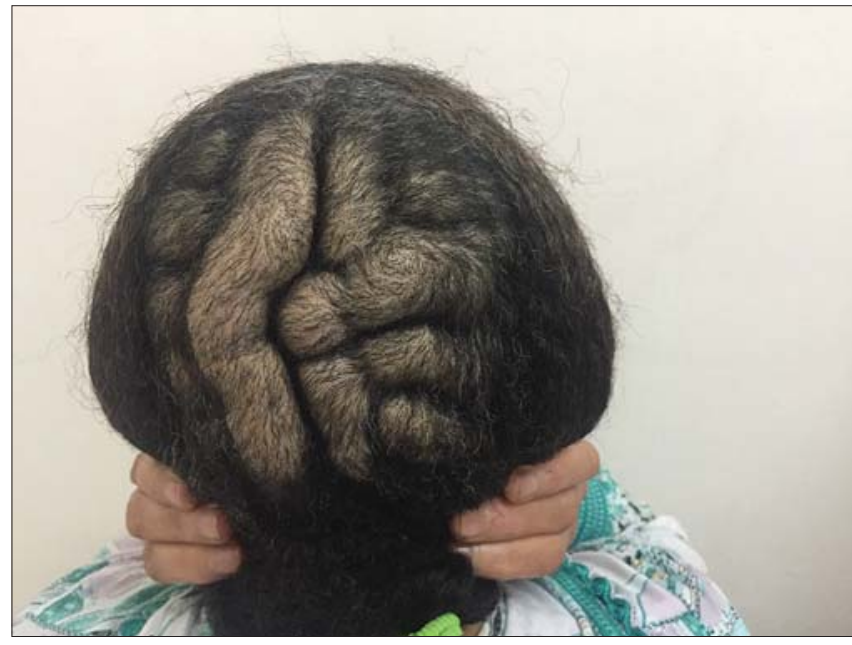

Figure 1: Clinical image of furrows and folds on the patient's scalp.

psychiatric or ophthalmological diseases [1]. Various etiologies have been proposed for the secondary CVG including local causes such as nevi, fibromas, or inflammatory changes and systemic disorders such as acromegaly, myxedema, cretinism, or leukemia, as well as to the systemic administration of drugs $[2,3]$. In our patient, any abnormalities in clinical findings or complementary laboratory examinations were found.

\section{Consent}

The examination of the patient was conducted according to the principles of the Declaration of Helsinki.

The authors certify that they have obtained all appropriate patient consent forms, in which the patients have given consent for images and other clinical information to be included in the journal. The patients understand that their names and initials will not be published and due effort will be made to conceal their identity, but that anonymity cannot be guaranteed. 
www.odermatol.com

\section{REFERENCES}

1. Sen F, Cagatay A, Ozsut H, Calangu S, Eraksoy H, Ozbey N. An unusual association of cutis verticis gyrata with empty sella. Eur J Intern Med. 2008;19:e23-5.

2. Baroudjian B, Lemarchand Venencie F, Osio A, Bagot M, Bourrat E. Cutis verticis gyrata localisé : chercher la tumeur! Ann Dermatol Vénéréol. 2014;141:S322-3.

3. Radwanski HN, Rocha Almeida MW, Pitanguy I. Primary essential cutis verticis gyrata - a case report. J Plast Reconstr Aesthet Surg. 2009;62:e430-3.

Copyright by Fatima-Zahra Kettani, et al. This is an open-access article distributed under the terms of the Creative Commons Attribution License, which permits unrestricted use, distribution, and reproduction in any medium, provided the original author and source are credited. Source of Support: Nil, Conflict of Interest: None declared. 